\title{
Fully Compliant Tensural Bistable Micro-mechanisms (FTBM)
}

D. L. Wilcox

dwilcox@sandia.gov

Larry L. Howell

Ihowell@byu.edu

Follow this and additional works at: https://scholarsarchive.byu.edu/facpub

Part of the Mechanical Engineering Commons

\section{Original Publication Citation}

Wilcox, D.L. and Howell, L.L., "Fully Compliant Tensural Bistable Micro-mechanisms (FTBM)," Journal of Microelectromechanical Systems, Vol. 14, No. 6, pp. 1223-1235, 25.

\section{BYU ScholarsArchive Citation}

Wilcox, D. L. and Howell, Larry L., "Fully Compliant Tensural Bistable Micro-mechanisms (FTBM)" (2005). Faculty Publications. 334.

https://scholarsarchive.byu.edu/facpub/334 accepted for inclusion in Faculty Publications by an authorized administrator of BYU ScholarsArchive. For more information, please contact ellen_amatangelo@byu.edu. 


\title{
Fully Compliant Tensural Bistable Micromechanisms (FTBM)
}

\author{
Daniel L. Wilcox, Member, ASME, and Larry L. Howell, Fellow, ASME
}

\begin{abstract}
A new class of bistable mechanisms, the fully compliant tensural bistable micromechanism (FTBM) class, is introduced. The class consists of linear bistable micromechanisms that undergo tension loads, in addition to the bending loads present, through their range of motion. Proof-of-concept designs fabricated in two different microelectromechanical systems (MEMS) surface micromachining processes were demonstrated. Three sets of refined designs within the FTBM class were designed using optimization methods linked with nonlinear finite element analysis (FEA), then fabricated and tested. Measured force and displacement performance are compared to values obtained by FEA. On-chip actuation of the bistable mechanisms was achieved using thermomechanical in-plane microactuators (TIMs). The FTBM class of bistable mechanisms explores a relatively new design space for fully compliant micromechanisms, and mechanisms from this class have promise in such applications as micro shutter positioning, microvalves, and electrical microrelays.

[1448]
\end{abstract}

Index Terms-Bistable mechanisms, compliant mechanisms, on-chip actuation.

\section{INTRODUCTION}

\section{A. Bistable Mechanisms}

A BISTABLE mechanism has three locations where no input force is required to maintain the device's state, including two stable equilibrium state and one unstable equilibrium state. In the classic "ball-on-a-hill" analogy shown in Fig. 1, the balls in positions $\mathrm{A}$ and $\mathrm{C}$ are located at local minima of the energy curve; without an input sufficient to push a ball over the hump in the curve, each will remain at the positions indicated. The ball at position $B$ is in an unstable equilibrium position; a small perturbation of its position will result in the ball transitioning either to Position A or C, depending on the sense of the input.

Bistable mechanisms can be partially compliant, where the device consists of one or more flexible segments as well as one or more traditional joints ${ }^{1}$, or fully compliant, where the mechanism achieves all of its motion and function from the motion

Manuscript received October 16, 2004; revised June 1, 2005. This work was supported in part by funding through a grant from the National Science Foundation program "XYZ on-a-chip" through Grant DMI-9980835, and by the MESA Institute at Sandia National Laboratories. Subject Editor N. R. Aluru.

D. L. Wilcox was previously affiliated with the Compliant Mechanisms Research (CMR) Group, Brigham Young University, Provo, UT 84602 USA. He is now with Sandia National Laboratories, Albuquerque, NM 87185 USA (e-mail: dwilcox@sandia.gov).

L. L. Howell is with the Department of Mechanical Engineering, Brigham Young University, Provo, UT 84602 USA (e-mail: lhowell@ byu.edu).

Digital Object Identifier 10.1109/JMEMS.2005.859089

${ }^{1}$ Traditional joints include pin joints, prismatic joints (sliders), and cams. These joints have rubbing surfaces between mating parts, thus introducing friction and wear.

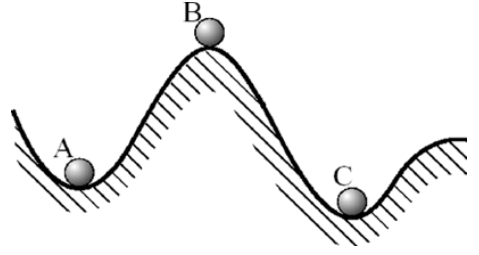

Fig. 1. "Ball-on-a-hill" analogy to bistable behavior.

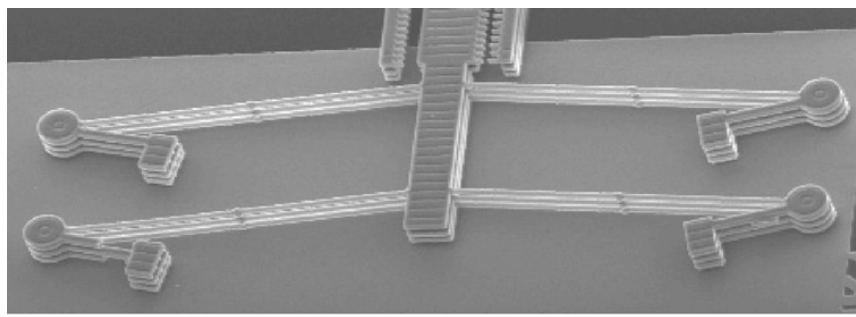

a)

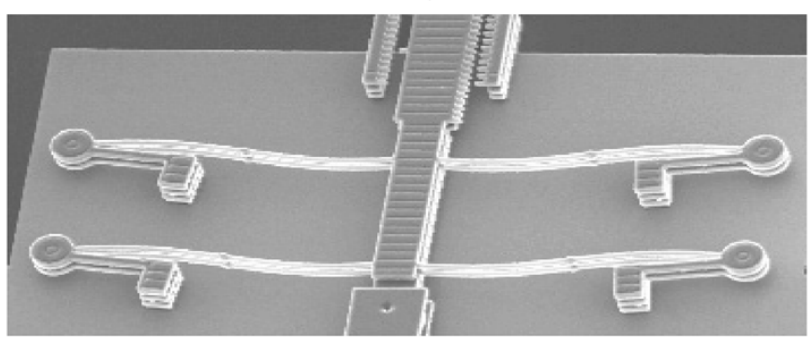

b)

Fig. 2. Two example FTBM designs: (a) one shown in its fabricated position and (b) one shown in its second stable position.

of compliant segments [1]. Configurations of compliant mechanisms which exhibit bistable behavior have been classified and presented in [2].

The simplest bistable mechanism at both the macro and micro levels is a snap-through buckled beam, such as those presented in [3], [4]. Bistable mechanisms have been developed at the micro level for several applications, such as microvalves [5], switches [6]-[10], and actuators [11]. The requirements for a microbistable mechanism depend on the application, but generally include requiring low actuation force and power, high cycle life, and predictable, repeatable motion. Because of the poor ratio of tolerances to device dimensions inherent to processes at the micro level, fully compliant microbistable mechanisms are very appealing. The bistable mechanisms presented in [3], [4], [8], [9], [11]-[13] are examples of those that can be defined as fully compliant. 


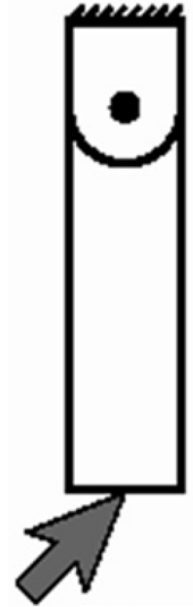

(a)

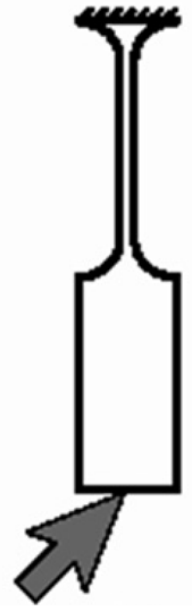

(b)

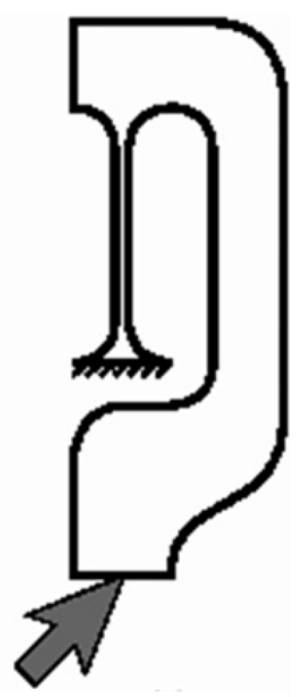

(c)
Fig. 3. Tensural (tensile flexural) pivot explanation, (a) standard pin joint, (b) compliant joint loaded in compression and bending, and (c) tensural pivot loaded in tension and bending [9].

\section{B. Purpose}

A new class of bistable mechanisms, inspired by the behavior of a modified folded beam suspension, greatly expands the design space for bistable mechanisms. The class consists of fully compliant bistable mechanisms which undergo tension loads in addition to or in place of compression loads. The mechanism class is called the fully compliant tensural bistable mechanism (FTBM) class. Scanning electron micrographs of example FTBMs, each shown in one of its stable positions, are shown in Fig. 2.

The majority of bistable mechanisms in the literature undergo compression and bending loads only. With the exception of the micromechanism presented in [9], there are no single-material in-plane bistable mechanisms that undergo tension loads. With segments loaded in tension, buckling is not a concern. The tensural pivots developed in [9] illustrate the benefit of segments loaded in tension and bending rather than compression and bending. In Fig. 3, the tensural pivot [see Fig. 3(c)] performs the same function as the compression-loaded joint [see Fig. 3(b)] but does not have the potential problems buckling could cause. The tensural pivot is much stiffer axially, which can be beneficial in the design of bistable mechanisms. The FTBM also uses the tensural pivot concept, but incorporates unique geometry and loading conditions to obtain the bistable behavior.

Prototype proof-of-concept configurations of the FTBM were designed using finite element analysis (FEA). The model was linked to optimization routines and refined, and a second generation of more efficient configurations of FTBM devices was designed, fabricated, and tested. Macro- and micro-FTBM proof-of-concept designs and three topologies of refined second generation micro mechanisms of the FTBM class are presented in this paper. Measured results are compared to the predicted values of force and displacement, and on-chip actuation is demonstrated.

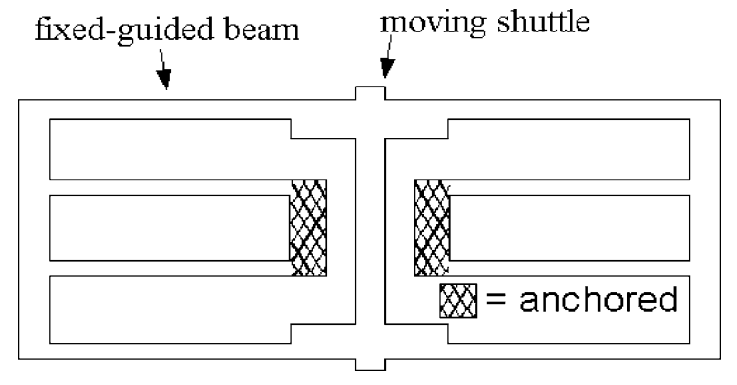

Fig. 4. The folded beam linear motion mechanism.

TABLE I

FTBM PROOF-OF-CONCEPT MACRO PROTOTYPE DESIGNS

\begin{tabular}{|c|c|c|}
\hline Variable & Design value & Prototype value \\
\hline \hline$L_{\mathcal{C}}$ (in.) & 5.0 & 5.0 \\
\hline$L_{S}$ (in.) & 3.0 & 3.0 \\
\hline$L_{S h}$ (in.) & 4.1 & 4.1 \\
\hline$t_{v}$ (in.) & 1.25 & 1.24 \\
\hline$t_{S}$ (in.) & 0.25 & 0.23 \\
\hline$t_{C}$ (in.) & 0.125 & 0.124 \\
\hline$L_{\text {OC }}$ (in.) & 1.0 & 1.0 \\
\hline$L_{\text {OS }}$ (in.) & 1.0 & 1.0 \\
\hline$\phi$ (deg.) & 8.0 & 8.0 \\
\hline$\theta$ (deg.) & 8.0 & 8.0 \\
\hline$h$ (part thickness; in.) & 0.5 & 0.5 \\
\hline
\end{tabular}

\section{FTBM DESIGN}

\section{A. Modified Folded Beam Suspension}

The FTBM class was inspired by the folded beam suspension which has many applications at the micro level. For example, a folded-beam structure acts as a compliant prismatic joint and as the restoring spring for most electrostatic comb drive actuators. A simple folded beam suspension is shown in Fig. 4. The folded beam mechanism is essentially a set of fixed-guided beams connected in series and acts as a linear spring. The pseudo-rigidbody model (PRBM) [1] of the left half of the layout is shown in Fig. 5(a). In the figure, $L_{1}=L_{2}$, and points A and B both follow the shape of the arc shown. Fig. 5(b) shows the case where $L_{1}$ and $L_{2}$ are not equal. It is clear from Fig. 5(b) that if the inner and outer flexible segments do not share the same length, the PRBM is a structure. Points A and B attempt to follow the independent paths indicated and motion is restricted. The compliant link lengths must be equal in the kinematic model or high stresses result. The fully compliant configuration would be capable of motion although the kinematic model would predict the device to be a structure, but high stresses are quickly introduced in the bending segments as they try to conform to the same path.

The function of a folded beam suspension with unequal compliant link lengths is greatly limited. While all the flexible segments undergo bending, the long and short segments are subjected to compression and tension, respectively. However, this 


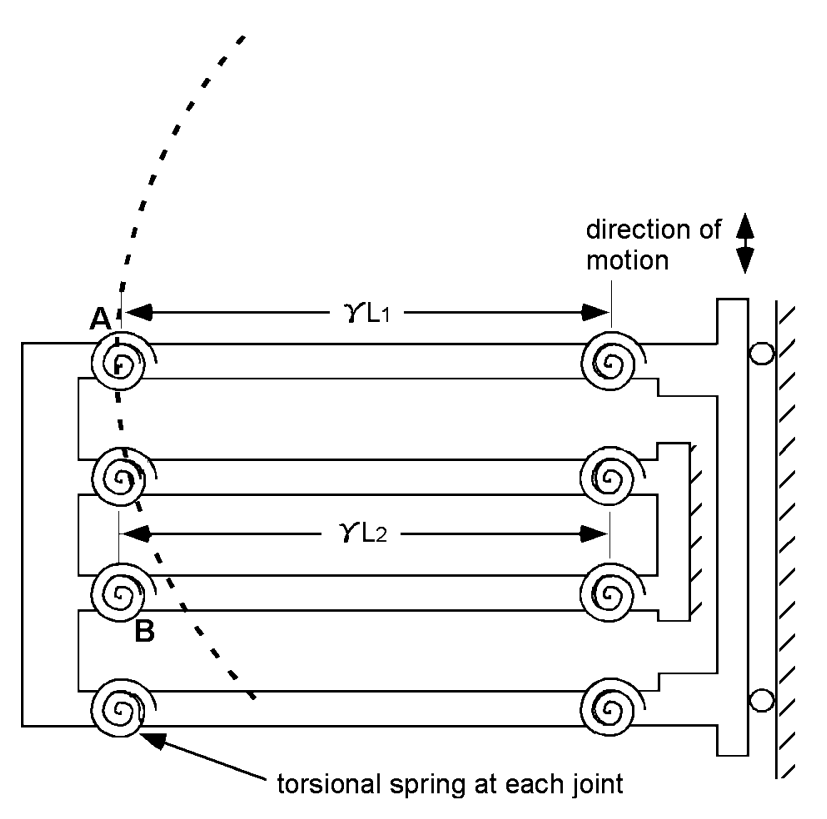

a)

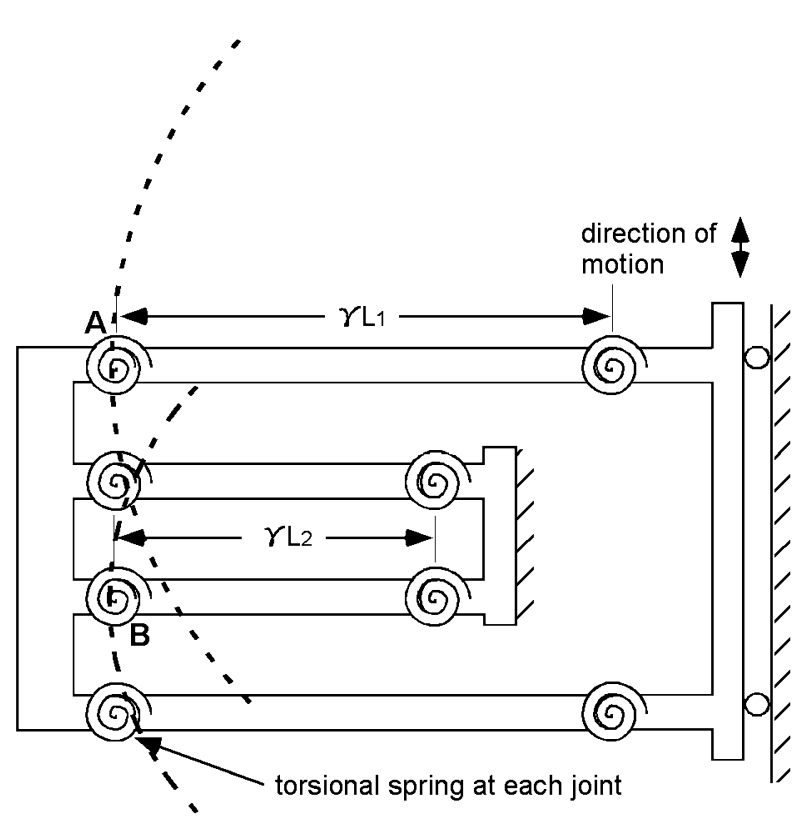

b)

Fig. 5. Folded beam PRBM half model. (a) Half model PRBM of Fig. 4 and (b) PRBM with different length segments.

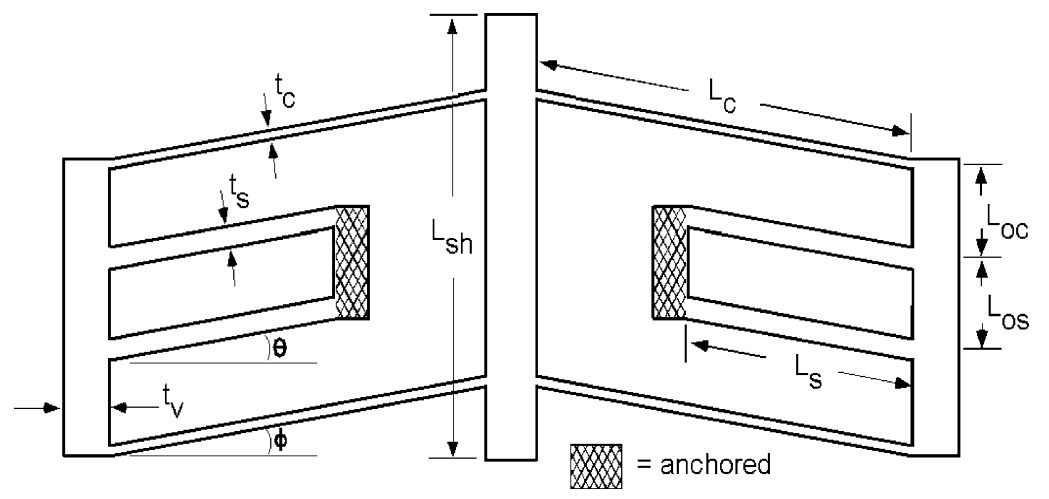

Fig. 6. Diagram and nomenclature of FTBM.

combined tension and bending loading in the shorter segments results in nonlinear force-displacement behavior that may be manipulated to create devices with particular desired behavior, such as bistability. This concept is exploited to create the FTBM class described in this paper.

\section{B. Initial FTBM Development}

Only certain configurations of the folded-beam suspension with unequal compliant link lengths exhibit bistable behavior, and identifying feasible designs with the specified complex behavior was accomplished using nonlinear finite element analysis combined with optimization routines. Fig. 6 shows the layout used to investigate the possibility of identifying variations of the folded beam suspension that exhibit bistable behavior. The leg lengths, thicknesses, and angles are independent design variables and each has an effect on whether the resulting mechanism configuration will be bistable or not. As indicated in the figure, the legs of the initial configuration are of different thicknesses and are set at an angle $\theta$. These two factors make the deflection behavior of the FTBM significantly different from that of the folded beam suspension upon which the mechanism class is based. The FTBM achieves bistable behavior in part as a result of stored strain energy as the uneven stresses in the flexible segments interact. Only specific configurations of the mechanism have a local minimum in the strain energy and thus exhibit bistable behavior.

While its bistable behavior is somewhat similar to centrally clamped snap through beams [3], the proof-of-concept layout's thicker inner legs and outer members (the segments of thickness $t_{v}$ and total length $2 L_{\mathrm{OC}}+L_{\mathrm{OS}}$ in Fig. 6) act in concert as a stiff spring. Also, while the longer flexible members $\left(L_{c}\right)$ are subjected to compression during the motion of the mechanism, the inner spring-like legs $\left(L_{s}\right)$ are subjected to tension, leading to the "tensural" term in the mechanism class name.

The nonlinear FEA model uses beam elements and applies a series of vertical displacement load steps. The reaction force is recorded at each load step. During initial FEA investigation of the modified folded beam, many designs with a positive angle $\theta$ were shown to exist that exhibit a softening-spring effect: Downward motion of the shuttle will cause the long flexible segments to buckle, causing an initial force peak followed by a reduction in force over a range of motion. Evidence of this 


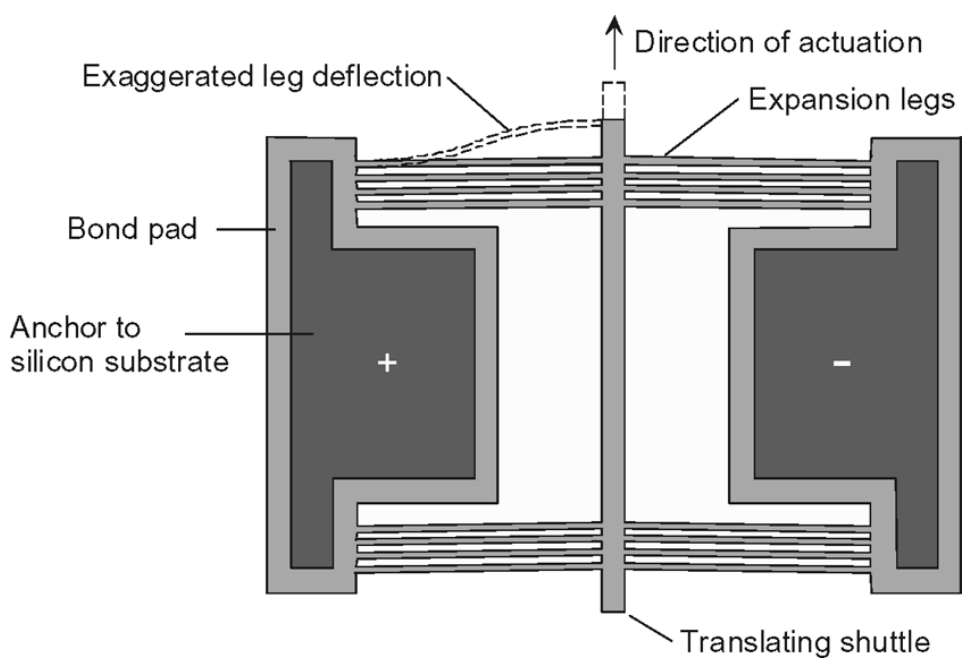

Fig. 7. A schematic of the TIM which was used to actuate the FTBM.

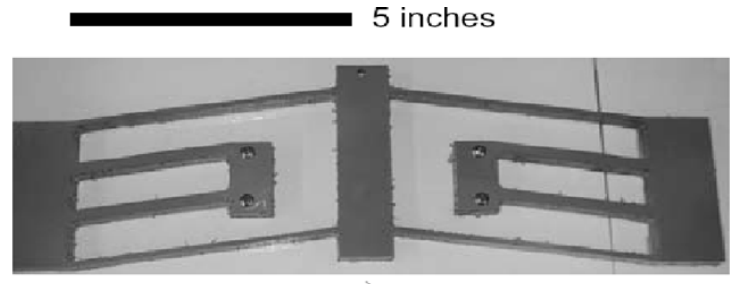

a)

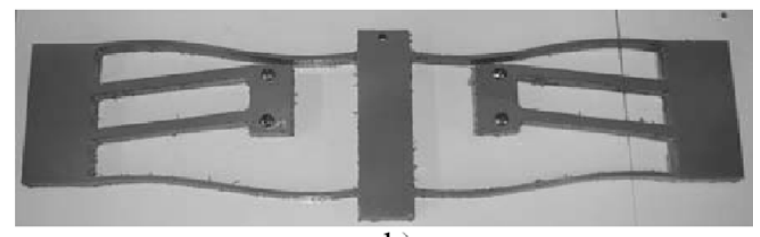

b)

Fig. 8. FTBM polypropylene prototype. (a) As machined. (b) Second stable position.

spring-softening effect is what initially inspired the pursuit of bistable configurations based on the folded beam suspension. Evidence of the spring-softening effect does not necessarily indicate the mechanism is bistable. For a device to be bistable, the energy curve corresponding to the device's motion must posses an unstable equilibrium position as indicated in Fig. 1; the required input force decreases to zero and the mechanism begins to exert an output force as it transitions past that point. The buckling of the long flexible segments combines with the uneven stresses in the flexible segments to result in bistability. Only certain values of the modified folded beam suspension's design variables result in this complex behavior. The FEA models were used to identify variable values that would result in bistable mechanism behavior.

\section{On-Chip Actuation}

Thermal actuators were selected and successfully demonstrated for on-chip actuation of the FTBM. Thermal actuators generate movement through the heating of their members. Generally, this movement is amplified by the geometry of the device. Both linear- and rotational-output [14] actuators have been demonstrated. Thermal actuators both of a single material [14]-[19] and multiple materials [20] have been developed. Of note is the thermomechanical in-plane microactuator (TIM), a linear-output actuator presented in [15], [18], [21]. The TIM consists of two arrays of slightly angled beams mirrored across a center shuttle. The legs of the TIM are heated by passing an electric current through them. The resulting joule-heating induced thermal expansion is amplified by the symmetry of the actuator. As the legs on each side of the shuttle expand, they are constrained by the shuttle, and the shuttle displaces forward. A TIM and its components are illustrated in Fig. 7. TIMs can be designed for a wide range of forces and displacements, and are used to actuate the devices in this work. Because the actuators are only needed to change the state of the FTBM not to maintain its state, the actuators are only on for short pulses, thus minimizing input power and secondary heating.

\section{FTBM PROOF-OF-CONCEPT}

Macro and micro proof-of-concept prototypes were constructed to demonstrate feasibility. Once the concept was demonstrated, the model was refined and linked to optimization routines resulting in improved devices, as described later.

\section{A. Macro proof-of-Concept Prototype: Predicted and Measured Results}

The initial FEA investigation of the modified folded beam identified several configurations exhibiting bistability. To validate the model, a macro prototype was designed and machined from polypropylene (see Fig. 8), and its force-deflection characteristics were measured using a linear potentiometer and compared with those predicted by the FEA model. Table I shows the model parameter values used for the prototype. Fig. 9 shows the force-deflection curve predicted by the model and the measured force-deflection curve. The upper measured curve corresponds to switching in the forward direction, and the lower measured curve corresponds to the return direction. 


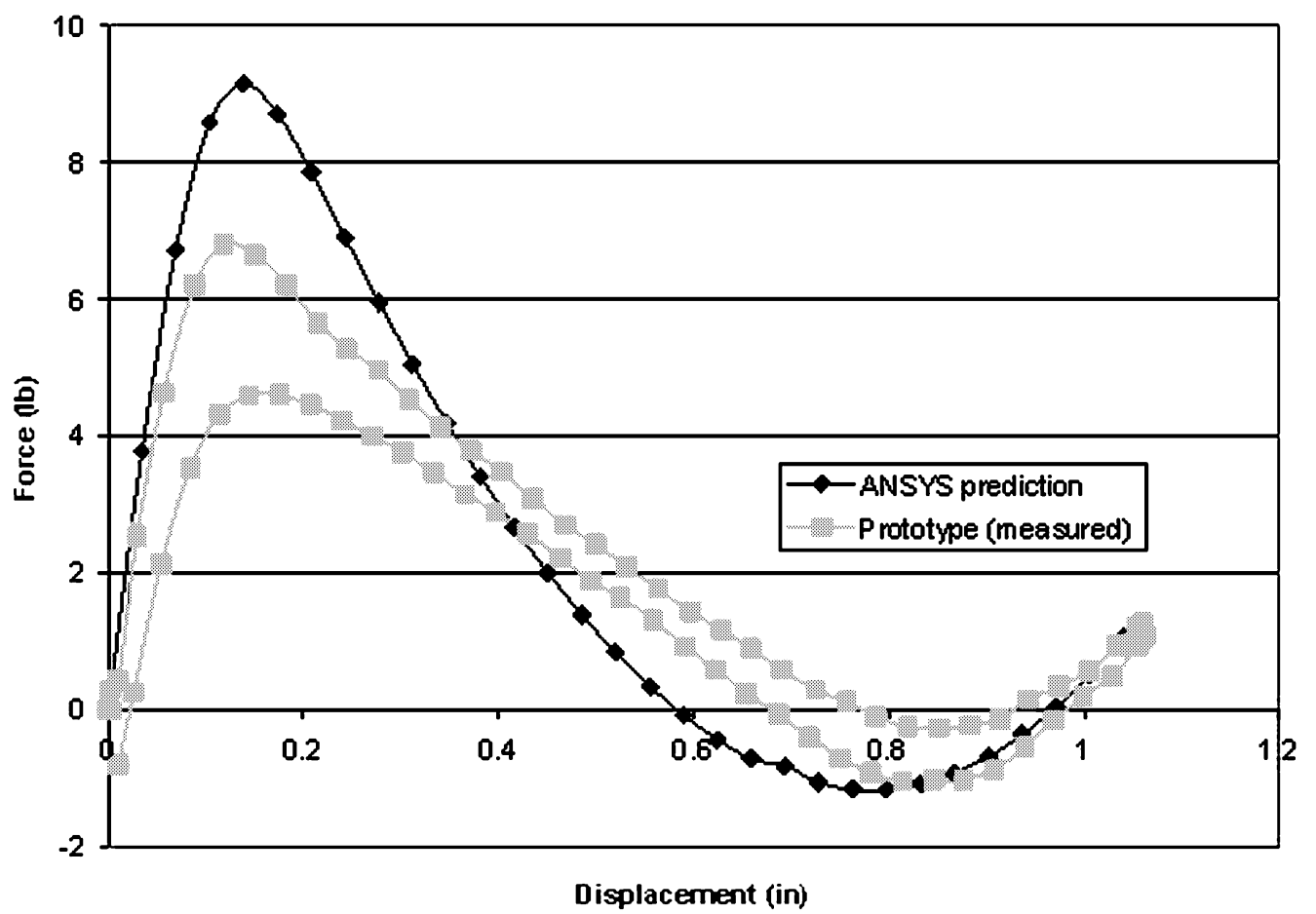

Fig. 9. Predicted and measured force-deflection of FTBM polypropylene prototype.

The measured values are lower than the predicted values. A likely contribution to the difference is imprecision in machining the prototype, resulting in values for $t_{c}$ and $t_{s}$ lower than the design values, as shown in Table I. Another factor is that the "stiff" elements (which were included in the boundary conditions in the FEA model) do have some elasticity. A difference in material properties between those assumed by the model and the actual prototype also would result in different values. A linear-elastic model was assumed, but polypropylene has some nonlinear material characteristics and is also susceptible to stress relaxation. Most importantly, in spite of the non ideal material properties, the proof-of-concept prototype performed its primary function: successfully validating that the model predicts the bistable behavior of the device.

\section{B. Micro proof-of-Concept Prototypes}

Several prototypes were fabricated at the micro level, and dimensions for three of these are listed in Table II. Fig. 10 shows prototypes $\mathrm{P} 1$ and $\mathrm{P} 2$ fabricated in the multi-user MEMS process (MUMPs) [22], one in the initial position and the other at its second stable equilibrium point. Fig. 11 shows design P3, as fabricated in Sandia National Laboratories' SUMMiT V process [23]. Design P3 was coupled with a thermal actuator for forward actuation, as shown in Fig. 12, and on-chip actuation of the prototype was successfully demonstrated.

\section{PARAmetric FTBM Model With OPtimization}

After the initial prototypes' bistable behavior was confirmed, a parametric model linking the FEA model to a user interface was developed to allow fast analysis of new variable values.

With this parametric model, multiple designs could be analyzed and those exhibiting bistability could be determined. The optimization is complicated by the nonlinear nature of the deflections and the regions of instability.

\section{A. Optimization Setup}

Gradient-based optimization routines were linked to the FTBM parametric model. The design space proved to be noisy, suggesting that nongradient based methods, such as simulated annealing, would be viable alternate approaches. The parameters in Tables I and II were selected as design variables in the optimization. Multiple gradient based optimization runs were performed using randomly generated starting points to explore the design space more extensively. Commercially available optimization codes available in MATLAB were used.

A goal of the bistable mechanism research in this work was to develop fully compliant bistable devices that have a high ratio of the maximum contact force, $F_{c}$, to the input force required to switch the device, $F_{s}$. The input force $F_{s}$ is the force exerted by the thermal actuator to switch the bistable mechanism from its first stable equilibrium position past the unstable equilibrium position to the second stable position. The contact force $F_{c}$ corresponds to the maximum output force available from the bistable mechanism. The force ratio $R_{F}$ is defined as

$$
R_{F}=\frac{F_{C}}{F_{S}} .
$$

The higher the values of $R_{F}$ that are achieved, the more efficient the device performance. The value of $F_{c}$ was also used as a constraint. When designs were generated that were not bistable, the resulting contact force, $F_{c}$, was negative, and the design iteration was discarded. To maximize the force ratio, $-R_{F}$ was selected as the objective function to be minimized. 
TABLE II

FTBM PROOF-OF-CONCEPT MICROPROTOTYPE DESIGNS

\begin{tabular}{|c|c|c|c|}
\hline Design variable & Prototype P1 & Prototype P2 & Prototype P3 \\
\hline \hline$L_{c}(\mu \mathrm{m})$ & 200 & 200 & 75 \\
\hline$L_{S}(\mu \mathrm{m})$ & 75 & 75 & 36 \\
\hline$t_{v}(\mu \mathrm{m})$ & 12 & 12 & 6 \\
\hline$t_{S}(\mu \mathrm{m})$ & 9 & 6 & 3 \\
\hline$t_{c}(\mu \mathrm{m})$ & 3 & 3 & 1 \\
\hline$L_{\text {oc }}(\mu \mathrm{m})$ & 30 & 30 & 15 \\
\hline$L_{\text {os }}(\mu \mathrm{m})$ & 20 & 20 & 8 \\
\hline$\phi($ deg. $)$ & 8 & 8 & 8 \\
\hline$\theta($ deg. $)$ & 6 & 10 & 8 \\
\hline$h$ (part thickness; $\mu m)$ & 3.5 & 3.5 & SUMMiT V \\
\hline Process & MUMPs & MUMPs & poly3,poly4 \\
\hline Layers used & poly1-2 & poly1-2 \\
& laminate & laminate & \\
\hline
\end{tabular}

TABLE III

SET 1 REFINED DESIGNS

\begin{tabular}{|c|c|c|}
\hline Design variable & Design 1A & Design 1B \\
\hline$L_{c}(\mu m)$ & 414.3 & 105.60 \\
\hline$L_{S}(\mu m)$ & 91.08 & 24.32 \\
\hline$t_{v}(\mu m)$ & 20.0 & 8.96 \\
\hline$t_{S}(\mu m)$ & 4.74 & 12.745 \\
\hline$t_{c}(\mu m)$ & 3.1 & 1.8 \\
\hline$L_{O C}(\mu m)$ & 42.8 & 9.67 \\
\hline$L_{O S}(\mu m)$ & 25.0 & 25 \\
\hline$\phi($ deg. $)$ & 10.4 & 8.0 \\
\hline$\theta$ (deg.) & 12.0 & 5.45 \\
\hline$h$ (part thickness; $\mu m$ ) & 6.0 & 4.5 \\
\hline SUMMiT layers used & $\begin{array}{c}\text { poly } 1-2, \text { poly } 3, \\
\text { poly } 4\end{array}$ & poly3, poly4 \\
\hline Predicted $R_{F}$ & 0.29 & 0.28 \\
\hline
\end{tabular}

Other optimization constraints chosen included limits on the displacement of the mechanism (the total displacement and the location of the unstable equilibrium point), the maximum allowable switching force, and the maximum stress.

\section{REFINED DESIGNS}

Several FTBM topologies (described later) were each optimized to find refined bistable mechanism designs with high force ratios $\left(R_{F}\right)$. A parametric FEA model for each topology was created and linked to the optimization algorithms. Refined designs for three topologies within the FTBM class are presented in this section. A topology may have different designs (shapes) within that topology; the designs within a topology are called a "set."

The first topology (Set 1) is the same as that used for the macro- and microprototypes and is a half model of Fig. 6. The layout of the second set (see Fig. 13), Set 2, resulted from eliminating the segment $L_{\mathrm{os}}$ (see Fig. 6) and constraining $L_{\mathrm{oc}}$ to be as short as possible and still be fabricated in-plane. While the layout of Set 1 was a half model, Set 2 was modeled as a quarter model. 


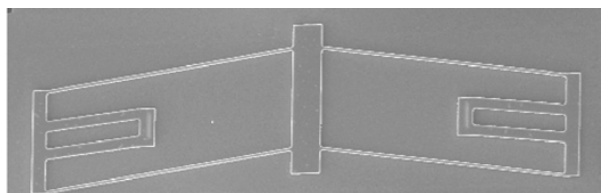

a)

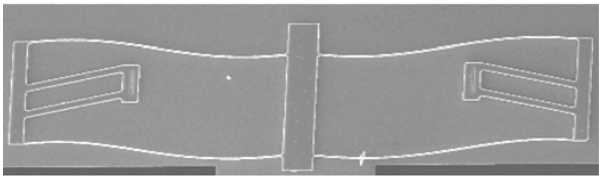

b)

Fig. 10. FTBM polypropylene prototypes (a) P1 as fabricated and (b) P2 in second stable position.

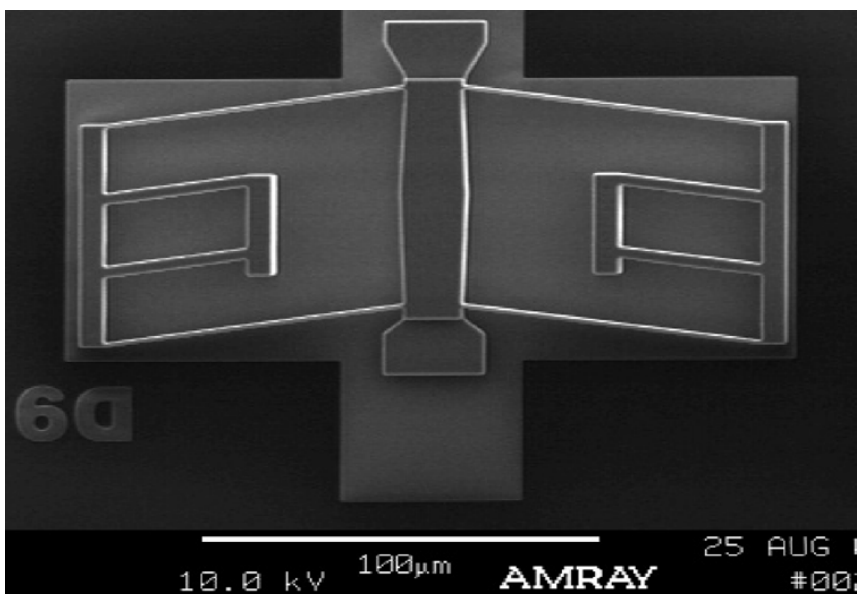

Fig. 11. FTBM prototype P3 as fabricated in SUMMiT V process.

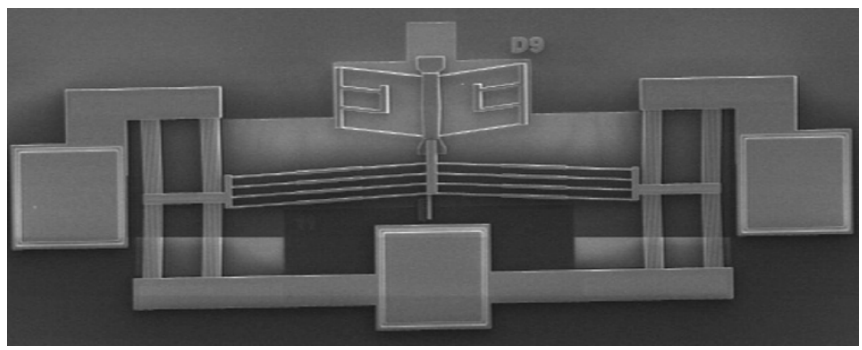

Fig. 12. FTBM prototype P3 with ATIM actuator as fabricated in Sandia National Laboratories' SUMMiT V.

The optimization of Set 2 consistently drove the segment length $L_{\mathrm{Oc}}$ to near its minimum allowable value as set by the minimum in-plane spacing possible between segments $L_{c}$ and $L_{s}$. Therefore, for Set 3 the length of segment $L_{\mathrm{OC}}$ was constrained to zero, as shown in Fig. 14. The endpoints of the segments $L_{c}$ and $L_{s}$ are thus coincident and are rigidly connected together. While the devices in the first two sets can be fabricated in a single-layer process, the Set 3 designs could be fabricated in a multi-layer, planarized surface micromachining process such as SUMMiT V. The upper segment passes over the underlying tensural pivot during the motion of the device (see Fig. 21). As shown in Fig. 14, a stiffer center region also was added to the

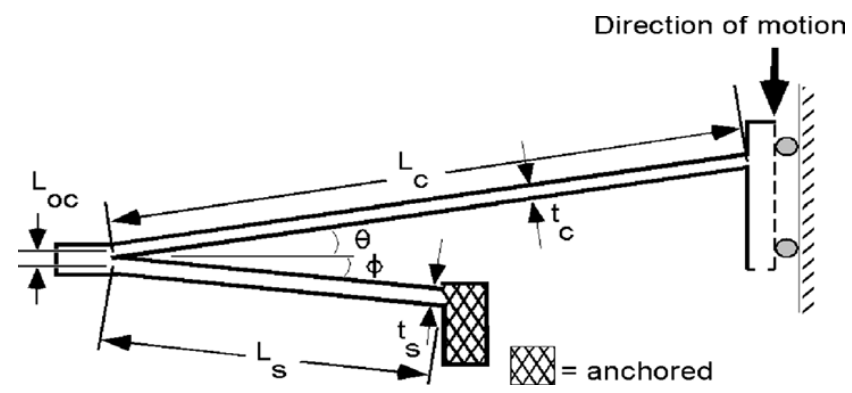

Fig. 13. Layout used for Set 2 designs (quarter model).

TABLE IV

SET 2 REFINED DESIGNS

\begin{tabular}{|c|c|c|}
\hline Design variable & Design 2A & Design 2B \\
\hline$L_{c}(\mu m)$ & 116.58 & 101.23 \\
\hline$L_{s}(\mu m)$ & 25 & 25 \\
\hline$t_{s}(\mu m)$ & 3.5 & 3.5 \\
\hline$t_{c}(\mu m)$ & 1.5 & 1.8 \\
\hline$L_{O C}(\mu m)$ & 2.44 & 9.67 \\
\hline$\phi$ (deg.) & 12.83 & 7.39 \\
\hline$\theta$ (deg.) & 5.37 & 6.71 \\
\hline$h$ (part thickness; $\mu m)$ & 6.0 & 4.5 \\
\hline SUMMiT layers used & $\begin{array}{c}\text { poly1-2, poly3, } \\
\text { poly4 }\end{array}$ & poly3, poly4 \\
\hline Predicted $R_{F}$ & 0.32 & 0.33 \\
\hline
\end{tabular}

layout used for Set 3 in between two segments of length $L_{c}$. Experience has shown that mechanism configurations are better suited to bistable behavior when the buckling load perpendicular to the direction of motion was increased. The bending in the two segments $L_{c}$ (which is directly related to the switching force required) was not increased significantly by the addition of segment $L_{\mathrm{cs}}$ but the buckling load of segment $L_{C}-L_{\mathrm{CS}}-L_{C}$ was increased. In short, a bistable mechanism with a good force ratio $R_{F}$ was shown to be one that is soft in the direction of motion shown in Figs. 13 and 14 and stiff in the transverse direction. This is also evident in the analysis of the bistable configurations presented in [2].

In Sets $1-3$ of the FTBM class, segment $L_{s}$ (the tensural pivot) undergoes tension and bending loads, while segment $L_{c}$ (segment $L_{C}-L_{C S}-L_{C}$ in Set 3 ) undergoes compression and bending loads.

Using the topology of Set 1 , the optimization achieved predicted $R_{F}$ values up to 0.29 . Two Set 1 designs were selected for fabrication in SUMMiT V, with variables as listed in Table III. The selected designs in Set 2 are listed in Table IV. Slightly higher force ratios were achieved by the optimization, but none exceeded 0.33. The fabricated designs from Set 3 (Designs 3A, 3B, 3C), listed in Table $\mathrm{V}$, showed significantly better force ratios than for the other device sets. The mechanism with the highest ratio is Design 3A with a predicted $R_{F}$ of 0.97 . 
TABLE V

SET 3 REFINED DESIGNS

\begin{tabular}{|c|c|c|c|}
\hline Design variable & Design 3A & Design 3B & Design 3C \\
\hline$L_{c}(\mu m)$ & 40.0 & 40.0 & 35.0 \\
\hline$L_{s}(\mu m)$ & 30.0 & 40.0 & 25.0 \\
\hline$t_{s}(\mu m)$ & 1.02 & 1.24 & 1.24 \\
\hline$t_{c}(\mu m)$ & 1.50 & 1.50 & 1.53 \\
\hline$L_{c S}(\mu m)$ & 71.42 & 50.0 & 30.0 \\
\hline$t_{c s}(\mu m)$ & 4.0 & 2.93 & 3.27 \\
\hline$\phi($ deg. $)$ & 1.46 & 1.253 & 2.87 \\
\hline$\theta$ (deg.) & 4.2 & 3.63 & 4.5 \\
\hline $\begin{array}{c}h_{\mathrm{c}} \text { (out of plane thickness } \\
\text { of segment } L_{c} ; \mu m \text { ) }\end{array}$ & 4.5 & 4.5 & 4.5 \\
\hline $\begin{array}{c}h_{S} \text { (out of plane thick- } \\
\text { ness of segment } L_{S} ; \mu m \text { ) }\end{array}$ & 2.5 & 2.25 & 2.25 \\
\hline SUMMiT layers used & $\begin{array}{c}\text { seg. } L_{C}: \\
\text { poly3,poly4 } \\
\text { seg. } L_{s}: \text { poly1-2 }\end{array}$ & $\begin{array}{c}\text { seg. } L_{C}: \\
\text { poly3, poly4 } \\
\text { seg. } L_{S}: \text { poly1-2 }\end{array}$ & $\begin{array}{c}\text { seg. } L_{C}: \\
\text { poly3,poly4 } \\
\text { seg. } L_{S}: \text { poly1-2 }\end{array}$ \\
\hline Predicted $R_{F}$ & 0.97 & 0.82 & 0.72 \\
\hline
\end{tabular}

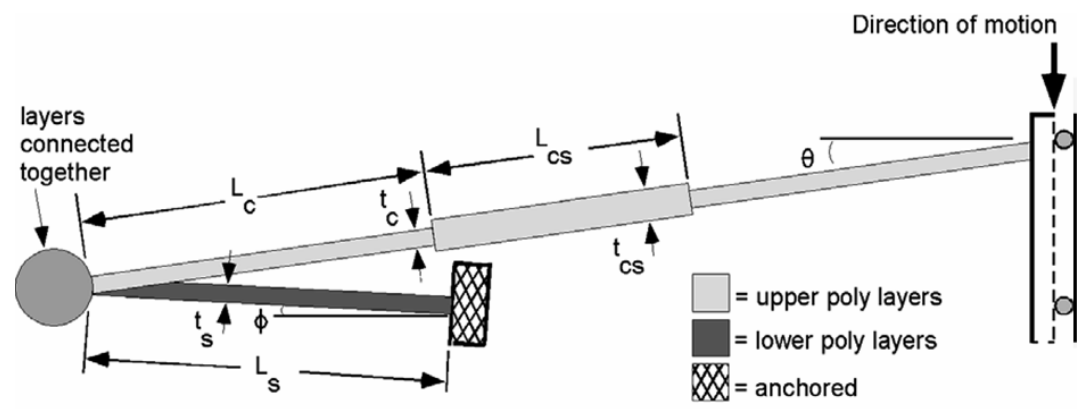

Fig. 14. Layout used for Set 3 designs (quarter model).

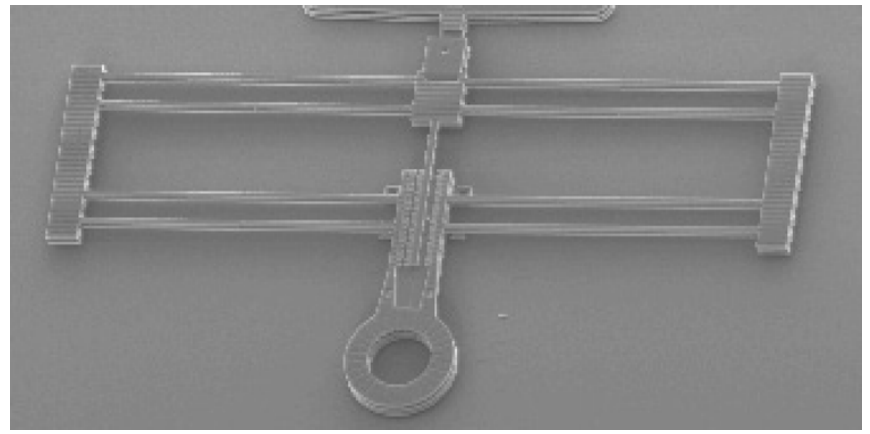

Fig. 15. Example of floating in situ force gauges used to measure bistable mechanism switching forces.

\section{A. Design Considerations}

There is an overetch of in-plane linewidths inherent to the SUMMiT V process. A fabricated segment will be narrower than the designed segment because of this overetch. If the

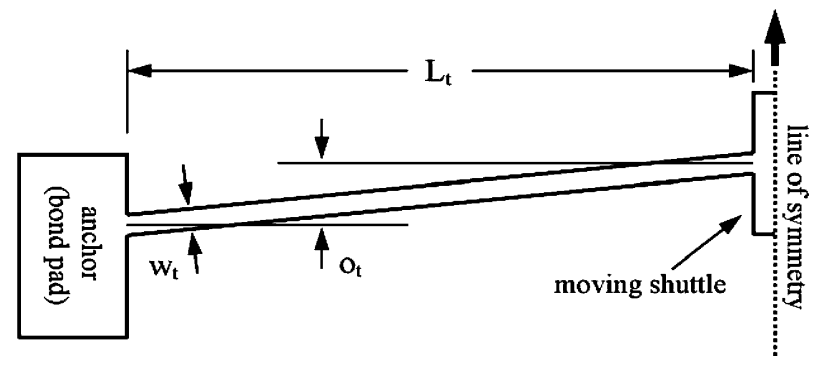

Fig. 16. TIM design layout.

overetch per side is $e_{0}$, a segment drawn with an in-plane thickness $t$ will be fabricated at an in-plane thickness $t_{0}$, where

$$
t_{o}=t-2 \times e_{o}
$$

For the designs in this work fabricated in SUMMiT V, an overetch of $0.1 \mu \mathrm{m}$ per side was accounted for in the analysis. 
TABLE VI

TIM DESIGNS FOR ACTUATION OF SET 3

\begin{tabular}{|c|c|c|c|c}
\hline & Design T1 & Design T2 & Design T3 & Design T4 \\
\hline \hline$L_{t}$ & 299 & 173 & 227 & 135 \\
\hline$o_{t}$ & 4.73 & 2.08 & 2.64 & 1.57 \\
\hline$w_{t}$ & 3.6 & 2.4 & 2.79 & 1.62 \\
\hline$n_{t}$ (number of legs) & 2 & 2 & 2 & 4 \\
\hline $\begin{array}{c}\text { h (out-of-plane } \\
\text { thickness; } \mu \mathrm{m})\end{array}$ & 6.5 & 6.5 & 6.5 & 6.5 \\
\hline SUMMiT V layers & poly3,poly4 & poly3,poly4 & poly3,poly4 & poly3,poly4 \\
\hline
\end{tabular}

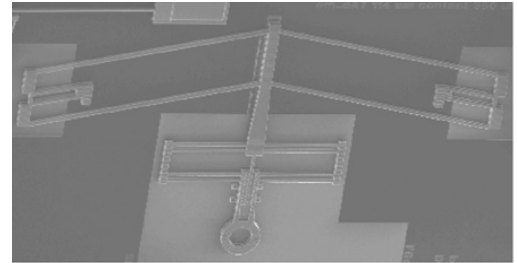

a)

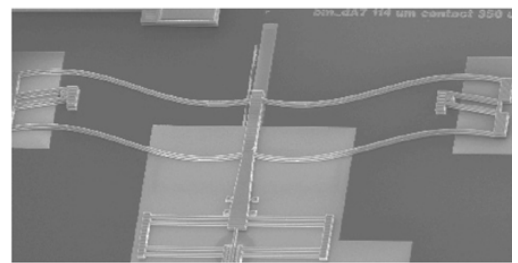

b)

Fig. 17. Set 1 bistable mechanisms: (a) Design 1A and (b) Design 1A switched position.

The in-plane thicknesses listed in the tables for Sets 1-3 are the nominal values for $t$.

\section{B. Measurement Methods}

For each bistable mechanism, a floating force gauge (Fig. 15) tailored to the expected force ranges was designed using the methods described in [24]. The force is proportional to the deflection of the force gauge. Each force gauge is connected to the mechanism via a floating pin joint similar to those in [25]. For displacement measurements, a vernier with $0.375 \mu \mathrm{m}$ resolution was integrated with each force gauge and bistable device. Software for quick semi-automated optical calibration and measurement of the displacement of the force gauge and switch from a series of optical images was also developed and utilized.

\section{On-Chip Actuation}

Designs 3A, 3B, and 3C listed in Table $\mathrm{V}$ were also fabricated with forward and return TIMs. The TIMs used to actuate these mechanisms are described by Fig. 16 and Table VI. The TIM legs were fabricated in poly 3 and poly4, with the connecting oxide cut as wide as possible within the SUMMiT V design rules [23]. The number of legs refers to the number of legs on each side of the shuttle.

\section{RESULTS}

The bistable behavior and force-displacement relationships predicted by the FEA model were compared with measured results. The following testing was performed on fabricated designs from each set:

- bistable behavior verification using micro probe actuation;

- measurement of stable equilibrium positions;
- force-displacement relationship measurements using in situ force gauges;

- on-chip actuation.

Testing demonstrated that all the designs from Sets 1, 2, and 3 exhibited bistable behavior. Design layouts without force gauges were slowly snapped forward and back with microprobes to find the unstable equilibrium point (USP) and second stable position (SSP). Each mechanism was actuated slowly to the USP, where it transitioned to the SSP. This process was also performed in the reverse direction. The motion was captured with a CCD camera, and the location of each mechanism's shuttle in the video frame just before the snap was used to measure the location of the USP, and subsequent frames were used to measure the location of the SSP.

To measure the force-displacement relationships, the force gauges were pulled with microprobes on an optical probe station. The motion was captured on video and motion of the device and the deflection of the force gauge were measured. It was possible to measure the force over the range of motion with an increasing actuation force, but force measurements are not available in the unstable snapping range. Results, including micrographs and plots, are given in this section for one design from each FTBM set. The $x$ and $y$ error bars on Figs. 18, 20, and 22 correspond to one standard deviation of force and displacement, respectively.

Design 1A from Set 1 is shown in its two stable equilibrium positions in Fig. 17. The force-displacement relationship predicted by FEA and the measured results for this design are shown in Fig. 18.

Design 2A from Set 2 is shown in its fabricated position and Design 2B is shown in its second stable position in Fig. 19. The main difference between Designs $2 \mathrm{~A}$ and $2 \mathrm{~B}$ is that segment $L_{c}$ in Design $2 \mathrm{~A}$ is longer and set at a greater angle than in Design 


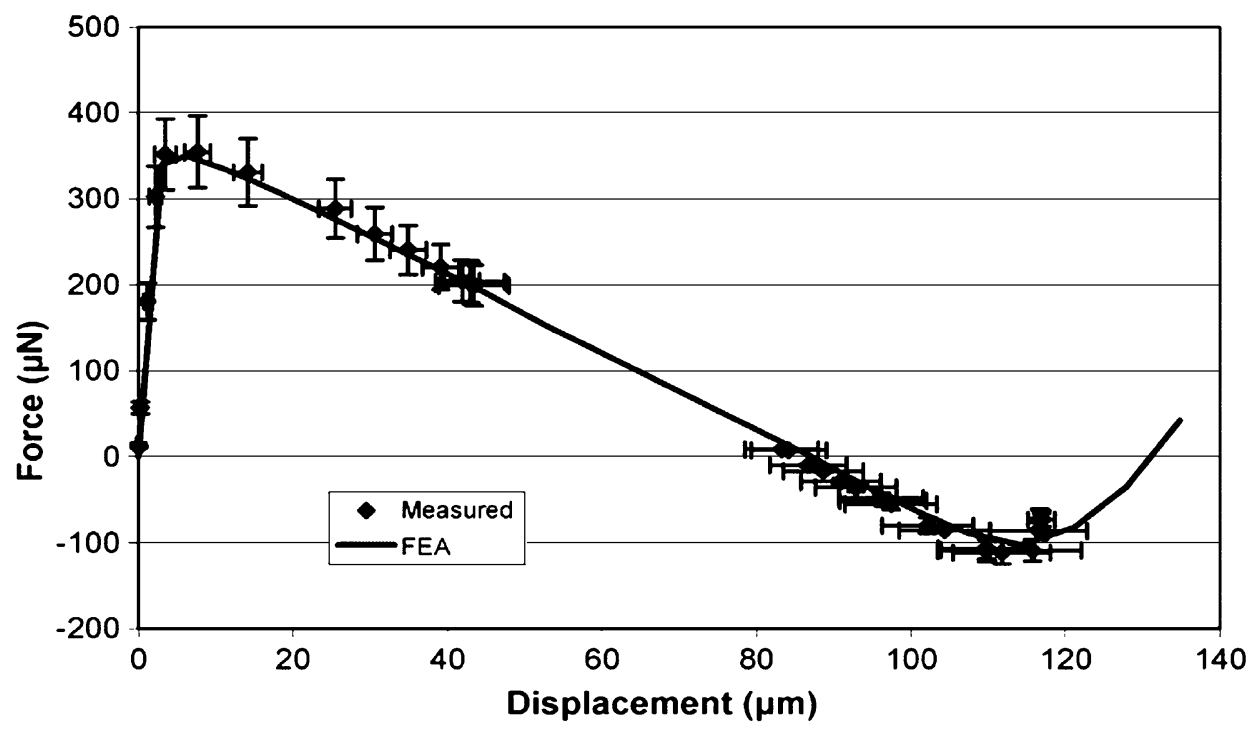

Fig. 18. Design 1A predicted and measured force and displacement. The $x$ and $y$ error bars correspond to one standard deviation of force and displacement, respectively.
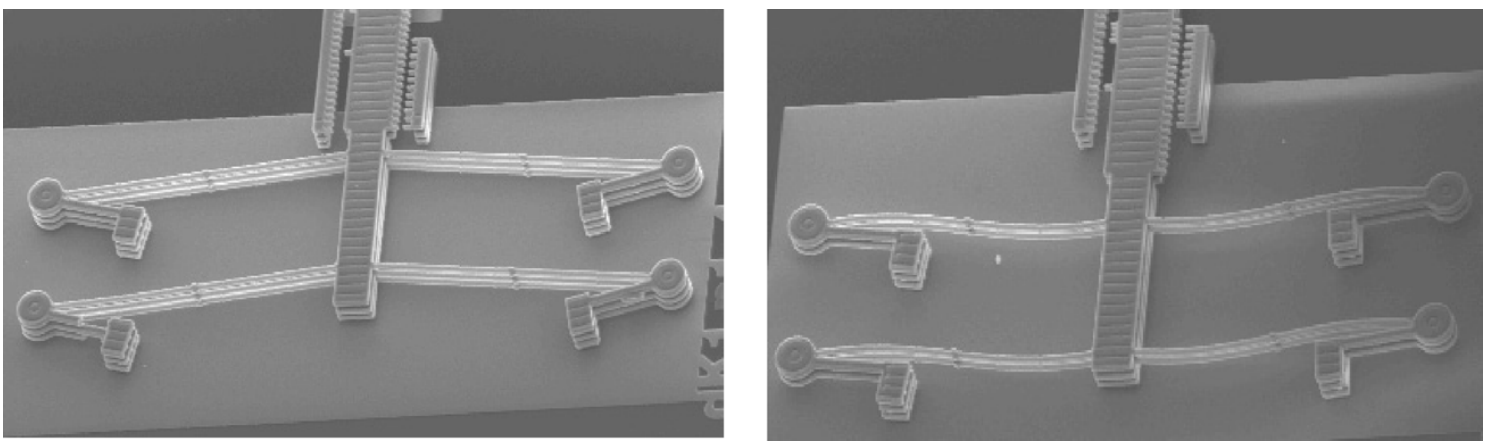

Fig. 19. Set 2 designs: (a) Design 2A in the fabricated position and (b) Design 2B in the second stable equilibrium position.

TABLE VII

SET 3 ACTUATION

\begin{tabular}{|c|c|c|c|c|c|c|}
\hline & \multicolumn{2}{|c|}{ Design 3A } & \multicolumn{2}{c|}{ Design 3B } & \multicolumn{2}{c|}{ Design 3C } \\
\hline & Forward & Return & Forward & Return & Forward & Return \\
\hline \hline Current (mA) & 13.9 & 13.4 & 14 & 11.7 & 14 & 13.5 \\
\hline Voltage (V) & 7.63 & 7.15 & 7 & 4.97 & 8.5 & 4.95 \\
\hline
\end{tabular}

2B. The predicted and measured force and displacement results for Design 2B are shown in Fig. 20.

Design 3A from Set 3 is shown in its two stable positions in Fig. 21. The predicted and measured force and displacement results are shown in Fig. 22.

On-chip actuation of Designs 3A, 3B, and 3C was achieved using an HP 4145 power supply as a current source. The current and voltage required to switch each device are listed in Table VII.

The parametric model for each set was verified in that all fabricated devices from all three sets proved to be bistable. The models also served an unexpected secondary purpose of identifying issues that may lead to lower than predicted actuation and contact forces for some designs. Except for Design 1A, the switching and contact forces and the force ratio for the devices were not as high as the predicted values. Any in-plane rotation of the shuttle or out-of-plane motion of the shuttle would reduce the observed force. The force gauges were coupled to the bistable switches via a floating pin joint to minimize any moment transfer, but any eccentric force load on the force gauge could still be transferred to the bistable device through the pin joint, possibly causing the bistable mechanism to follow a path of lower energy storage. Out-of-plane buckling has also been identified as a contributing factor between the measured and predicted force magnitude. More details on the analysis of these factors can be found in [26].

The USP was measured while switching each device in both directions included on the force displacement plot. As evident on Figs. 18, 20, and 22, hysteresis was evident in the motion of each device. 


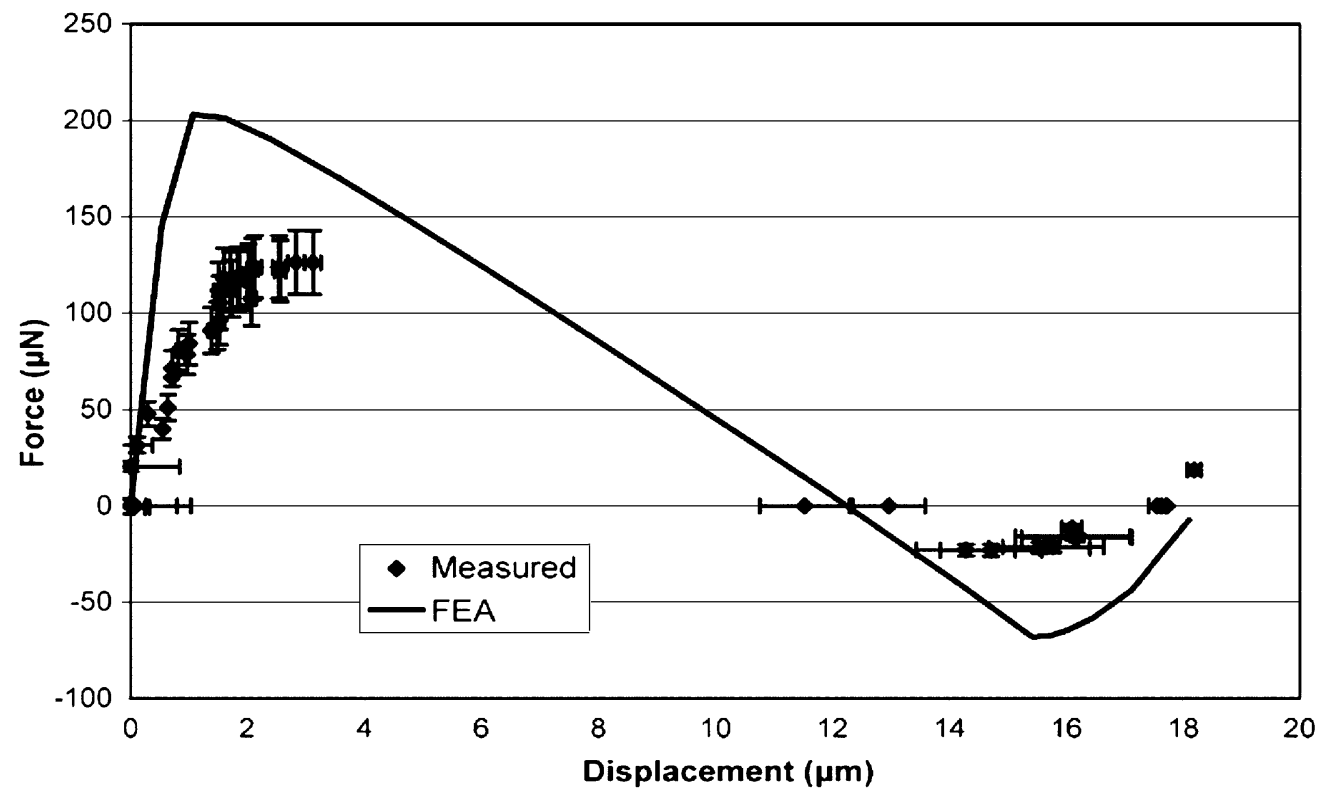

Fig. 20. Design 2B predicted and measured force and displacement. The $x$ and $y$ error bars correspond to one standard deviation of force and displacement, respectively.

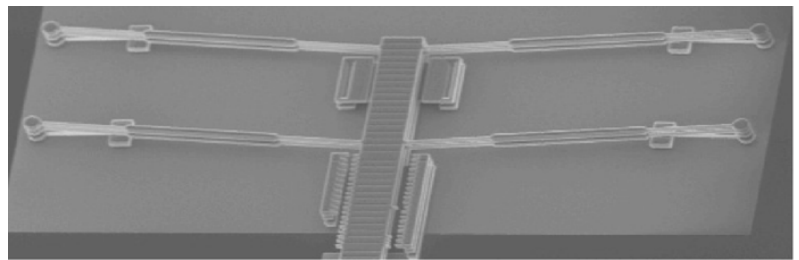

a)

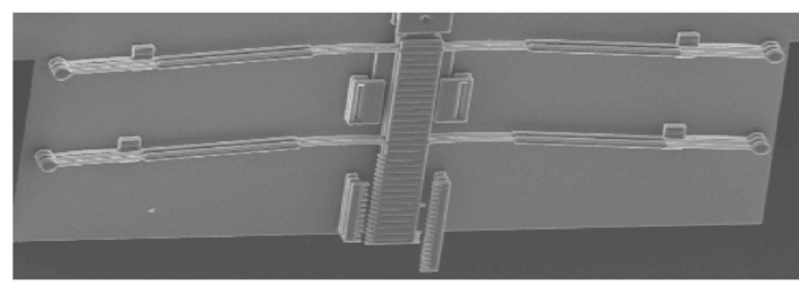

b)

Fig. 21. Set 3 designs: (a) Design $3 \mathrm{~A}$ and (b) Design 3A switched position.

Some of the designs in Set 3 exhibited an uneven switch past the USP, which may have contributed to the lower-than-expected force values shown in Fig. 22. Fig. 23 illustrates the phenomenon for Design 3A. As the thermal actuator pushed the bistable mechanism, the four legs did not all snap through at the same time, possibly due to a slight rotation of the shuttle or leg contact with the substrate. The tip of the shuttle on the thermal actuator can be seen in the top of each image in Fig. 22 as the device is actuated. Increasing the shuttle length, the distance between the legs, and the gap between the flexible segments and the substrate may limit the possible rotation and substrate contact and reduce this observed effect. This behavior was not observed with the design Sets 1 and 2. A scaled polypropylene prototype of Design 3A was made, but this behavior could not be duplicated at the macrolevel, even with applied eccentric loads. Some microscale phenomenon, such as stiction, may also be contributing to the behavior.

\section{CONCLUSION}

A new class of mechanisms, the fully compliant tensural bistable mechanism (FTBM) class, is introduced. Bistable mechanisms in this class have flexible segments that undergo tension loads in addition to compressive and bending loads.

A mechanism in the FTBM class has the following characteristics:

- the mechanism is fully compliant;

- the output displacement of the mechanism is linear and parallel to the mechanism's shuttle;

- at least one primary segment which undergoes deformation and stores strain energy is subjected to tension loads.

Several macro- and microprototypes exhibited bistability, and three sets of second-generation mechanisms fabricated in SUMMiT V belonging to the FTBM class were presented. Successful on-chip actuation of selected mechanisms was demonstrated. The measured results followed the predicted trends.

The FTBM class has all the advantages inherent to compliant mechanisms. The mechanism also lends itself well to multiple processes, including single- and multilayer processes. FTBMs can be optimized for desired forces and displacements, and multiple configurations are possible. The three sets of designs explored here are indicative that the design space of this new FTBM class is extensive. A subset of the FTBM class, Double-Tensural Bistable Mechanisms (DTBM), is presented in [27]

The parametric nonlinear finite element model combined with optimization algorithms was demonstrated to successfully navigate the large design space and to identify feasible bistable mechanism designs. This is particularly valuable considering the nonlinearities and instabilities associated with the complex behavior of bistable mechanisms. The primary purposes of the model, identifying feasible bistable configurations and 


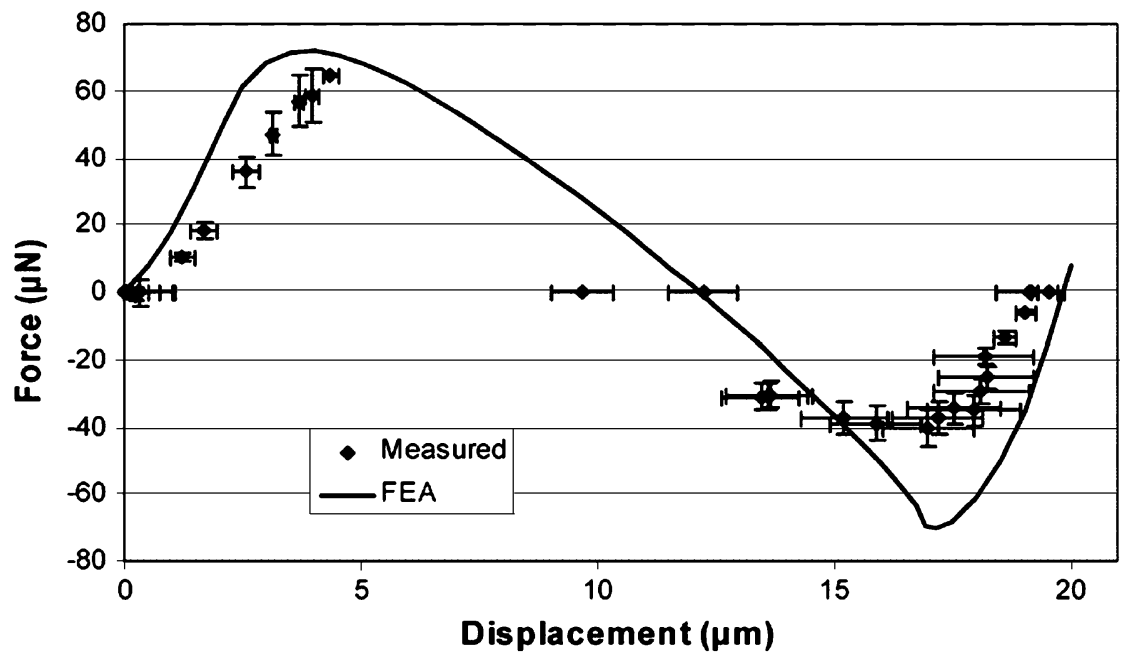

Fig. 22. Design 3A predicted and measured force and displacement. The $x$ and $y$ error bars correspond to one standard deviation of force and displacement, respectively.

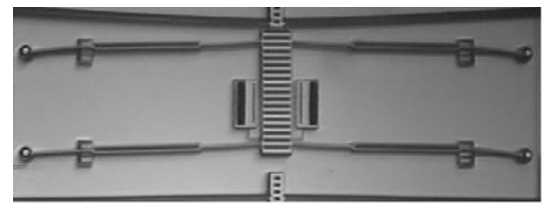

a)

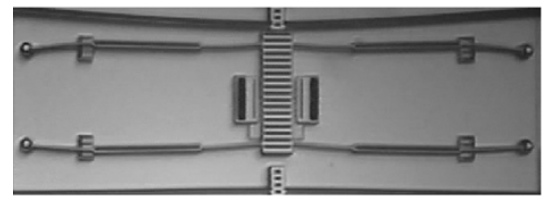

c)

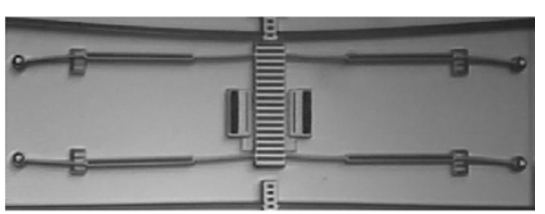

b)

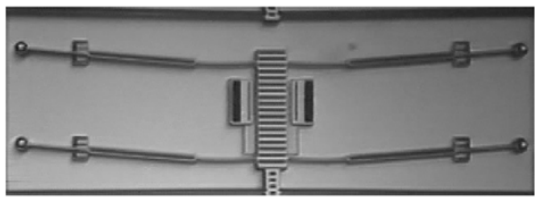

d)

Fig. 23. Uneven switching observed on Design 3A. (a) Just before switch, (b) lower left leg switched, (c) lower right leg switched, and (d) upper legs appeared to switch simultaneously.

predicting the location of stable and unstable equilibrium positions, were validated experimentally with multiple designs and topologies in various fabrication processes. Further refinement of the models may also help identify design issues that may lead to lower than predicted actuation and contact forces for some designs.

Possible applications for the FTBM class include electrical switches in microrelays, micro valves in micro fluidic applications, and shutter positioners in optical applications.

\section{REFERENCES}

[1] L. L. Howell, Compliant Mechanisms. New York: Wiley, 2001.

[2] B. D. Jensen and L. L. Howell, "Identification of compliant pseudorigid-body mechanism configurations resulting in bistable behavior," $J$. Mechan. Design, Trans. ASME, vol. 125, no. 4, pp. 701-708, 2003.

[3] J. Qiu, J. H. Lang, and A. H. Slocum, "A centrally-clamped parallelbeam bistable MEMS mechanism," in Proc. 14th IEEE International Conference on Micro Electro Mechanical Systems, 2001, pp. 353-356.

[4] M. Vangbo, "An analytical analysis of a compressed bistable buckled beam," Sens. Actuators, vol. 69, pp. 212-216, 1998.

[5] M. Capanu, J. G. Boyd IV, and P. J. Hesketh, "Design, fabrication, and testing of a bistable electromagnetically actuated microvalve," J. Microelectromech. Syst., vol. 9, no. 2, pp. 181-189, Jun. 2000.

[6] M. S. Baker, S. M. Lyon, and L. L. Howell, "A linear displacement bistable micromechanism," in Proc. 2000 ASME Design Engineering Technical Conference, DETC2000/MECH-14 117, 2000.
[7] B. D. Jensen, L. L. Howell, and L. G. Salmon, "Design of two-link, in-plane, bistable compliant micro-mechanisms," Trans. ASME, J. Mechan. Design, vol. 121, pp. 416-423, 1999.

[8] M. B. Parkinson, B. D. Jensen, and G. M. Roach, "Optimization-based design of a fully-compliant bistable micromechanism," in Proc. 2000 ASME Design Engineering Technical Conference, DETC2000/MECH-14 119, 2000.

[9] N. D. Masters and L. L. Howell, "A self-retracting fully-compliant bistable micro-mechanism," J. Microelectromech. Syst., vol. 12, no. 3 , pp. 273-280, Jun. 2003.

[10] E. J. J. Kruglick and K. S. J. Pister, "Bistable MEMS relays and contact characterization," Proc. IEEE Solid-State Sensor and Actuator Workshop, pp. 333-337, Jun. 8-11, 1998.

[11] H. Matoba, T. Ishikawa, C. J. Kim, and R. S. Muller, "A bistable snapping microactuator," in Proc. IEEE Micro Electro Mechanical Systems, Oisu, Japan, 1994, pp. 45-50.

[12] J. Qiu, J. H. Lang, and A. H. Slocum, "A curved-beam bistable mechanism," J. Microelectromech. Syst., vol. 13, no. 2, pp. 137-146, 2004.

[13] M. Hoffman, P. Kopka, and E. Voges, "Bistable micromechanical fiberoptic switches on silicon with thermal actuators," Sens. Actuators, vol. 78, pp. 28-35, 1999.

[14] J. T. Butler, V. M. Bright, and W. D. Cowan, "Average power control and positioning of polysilicon thermal actuators," Sens. Actuators, vol. 72, pp. 88-97, 1999.

[15] C. D. Lott, T. W. McLain, J. N. Harb, and L. L. Howell, "Thermal modeling of a surface-micromachined linear-displacement thermomechanical microactuator," Sens. Actuators A, Phys., vol. 101, no. 1-2, pp. 239-250, 2002.

[16] R. K. Messenger, "Modeling and Control of Surface Micromachined Thermal Actuators," M.S. Thesis, Brigham Young University, Provo, UT, 2004. 
[17] J. S. Park, L. L. Chu, E. Siwapornsathain, and A. D. Oliver, "Long throw and rotary output electro-thermal actuators based on bent-beam suspensions," in Proc. 13th IEEE International Conference on Micro Electro Mechanical Systems, 2000, pp. 680-685.

[18] R. Cragun and L. L. Howell, "Linear thermomechanical microactuators," Proc. Microelectromechanical Systems (MEMS) at the 1999 ASME International Mechanical Engineering Congress and Exposition, pp. 181-188, Nov. 1999.

[19] N. Mankame and G. Ananthasuresh, "Comprehensive thermal modeling and characterization of an electro-thermal-compliant microactuator," $J$. Micromech. Microeng., vol. 11, pp. 452-462, 2001.

[20] W. Riethmuller and W. Benecke, "Thermally excited silicon microactuators," IEEE Trans. Electron Devices, vol. 35, no. 6, pp. 758-762, 1998.

[21] L. L. Howell and T. W. McLain, "A little push," Mechan. Eng., pp. 58-59, Oct. 2002.

[22] D. A. Koester, R. Mahadevan, B. Hardy, and K. W. Markus, "MUMP's Design Handbook,", 2000. Rev. 5.0, Cronos Integrated Microsystems.

[23] Sandia National Laboratories, "SUMMiT V Five Level Surface Micromachining Technology Design Manual," Science and Technology Department, Microelectronics Development Laboratory, drt@sandia.gov. Version 1.2.

[24] J. W. Wittwer, T. Gomm, and L. L. Howell, "Surface micromachined force gauges: Uncertainty and reliability," J. Micromech. Microeng., vol. 12, pp. 13-20, 2002.

[25] D. C. Clements, L. L. Howell, M. Masters, and B. Weight, "Floating pin joints fabricated from two layers of polysilicon at the micro level," in Proc. Tenth World Congress on the Theory of Machines and Mechanisms, vol. 2, Oulu, Finland, Jun. 1999, pp. 874-879.

[26] J. W. Wittwer, "Simulation-Based Design Under Uncertainty for Compliant Microelectromechanical Systems," Ph.D. Dissertation, Brigham Young University, Provo, UT, Apr. 2005.

[27] D. L. Wilcox and L. L. Howell, "Double-tensural bistable mechanisms (DTBM) with on-chip actuation and spring-like post-bistable behavior," in Proc. 2005 ASME Int. Design Engineering Technical Conf., 2005. DETC2005-84697.

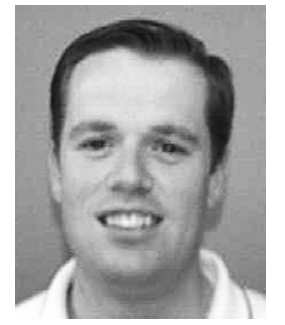

Daniel L. Wilcox received the B.S. and M.S. degrees in mechanical engineering from Brigham Young University, Provo, UT, in 2001 and 2004, respectively.

$\mathrm{He}$ is currently with the Integrated Surety Mechanisms II Department at Sandia National Laboratories, Albuquerque, NM.

Mr. Wilcox is a Member of the American Society of Mechanical Engineers (ASME) and Tau Beta Pi.

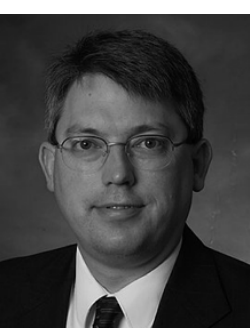

Larry L. Howell received the B.S. degree from Brigham Young University (BYU), Provo, UT, in 1987 and the M.S. and Ph.D. degrees from Purdue University, West Lafayette, IN, in 1991 and 1993, respectively.

$\mathrm{He}$ is currently Chair of the Department of Mechanical Engineering at BYU. Prior to joining BYU in 1994, he was a Visiting Assistant Professor a Purdue University, a finite-element analysis consultant for Engineering Methods, Inc., and an Engineer on the design of the YF-22 (the prototype of the U.S. Air Force F-22). He was a Director of the Utah Center of Excellence in Compliant Mechanisms and has over 15 patents granted or pending in the area of MEMS and compliant mechanisms. He is the author of the book Compliant Mechanisms (New York: Wiley).

Dr. Howell, a Fellow of the American Society of Mechanical Engineers (ASME) International, is the recipient of an NSF CAREER Award (1996-2000), the ASME Design Automation Conference Best Paper Award (1999), the MDI Software Award (1992), and is Chair of the ASME Mechanisms \& Robotics Committee. 